\title{
Toward decolonizing nursing: the colonization of nursing and strategies for increasing the counter-narrative
}

\author{
Elizabeth McGibbon, ${ }^{a}$ Fhumulani Mavis Mulaudzi,b Paula Didham,c Sylvia Bartond and Ann Sochane \\ aSt. Francis Xavier University, Antigonish, NS, Canada, bUniversity of Pretoria, Pretoria, South Africa, cWestem Regional \\ School of Nursing, Comer Brook, NL, Canada, dUniversity of Alberta, Edmonton, AB, Canada, eUniversity of Ottawa \\ School of Nursing, Ottawa, ON, Canada
}

\begin{abstract}
Although there are notable exceptions, examination of nursing's participation in colonizing processes and practices has not taken hold in nursing's consciousness or political agenda. Critical analyses, based on the examination of politics and power of the structural determinants of health, continue to be marginalized in the profession. The goals of this discussion article are to underscore the urgent need to further articulate postcolonial theory in nursing and to contribute to nursing knowledge about paths to work toward decolonizing the profession. The authors begin with a description of unifying themes in postcolonial theory, with an emphasis on colonized subjectivities and imperialism; the application of a critical social science perspective, including postcolonial feminist theory; and the project of working toward decolonization. Processes involved in the colonization of nursing are described in detail, including colonization of nursing's intellectual development and the white privilege and racism that sustain colonizing thinking and action in nursing. The authors conclude with strategies to increase the counter-narrative to continued colonization, with a focus on critical social justice, human rights and the structural determinants of health.
\end{abstract}

Key words: colonialism, critical social science perspectives, decolonization, feminist postcolonial theory, nursing, structural determinants of health.

There is a small but growing body of postcolonial feminist literature in nursing (Anderson 2002; Reimer Kirkham and Anderson 2002; Anderson et al. 2003; Browne, Smye and Varcoe 2005). This work has built upon, and extended, postcolonial discourses in the social sciences (cf. Fanon 1961; Said 1979; Collins 2005) and elucidated the relevance of postcolonial and other critical perspectives for informing decolonizing practices in nursing. Some nursing authors have emphasized that all forms of marginalization and discrimination are ethical concerns (Varcoe 2004). However, there is relatively little integration of postcolonial concepts and ideas into mainstream nursing discourse.

Correspondence: Elizabeth McGibbon, PhD, RN, Associate Professor, School of Nursing, St. Francis Xavier University, PO Box 5000, Antigonish, NS, Canada B2G 2W5.E-mail:<emcgibbo@stfx.ca>
The goals of this discussion article are to underscore the urgent need to further articulate postcolonial theory as it applies to nursing and to contribute to nursing knowledge about paths toward decolonizing the profession. The ideas are based on our research work together in a federally funded Decolonizing Nursing project. We begin with an overview of unifying themes in postcolonial theory, with an emphasis on feminist postcolonial theory. These discussions form the background for an analysis of processes involved in the colonization of nursing, including its embedded colonizing assumptions, the colonization of nursing's intellectual development, and white privilege and racism in the nursing profession. Such barriers play an integral role in explaining why postcolonial thinking has not yet taken hold in nursing. We conclude with strategies for increasing the counter-narrative to the thinking and action that support nursing's contin- 
ued participation in colonization. We recognize the vastness of the decolonizing project. However, it is important to disentangle some of these complex processes and continue to provide starting points for continued decolonization.

\section{UNIFYING THEMES IN POSTCOLONIAL THEORY}

The term 'postcolonial' refers to a constellation of interwoven processes and practices, rather than a discrete time period. Postcolonial theories have differing origins (e.g., anthropology, cultural studies, sociology) and hence differing foci. Postcolonial theory most importantly provides a framework and vocabulary for understanding the burden of history and how this history shapes present-day experiences and new forms of injustice (Browne et al. 2005). Postcolonialism is concerned with 'the unequal relations of power that are the legacy of a colonial past and neocolonial present, and the ways in which the cultures of dominant groups have redefined local meanings, and dictated social structures, including health care delivery systems' (Anderson et al. 2003, 197). Postcolonial theoretical perspectives involve vocabularies and analytical lenses that critique the historical origins of colonization, neo-colonialism and their imperialist underpinnings.

Colonialism, in particular, refers to that form of empirebuilding imperialism in which geographic regions outside of Europe were occupied by European countries and 'settled', a strategy that was justified through a racialized colonial discourse about the necessity of civilizing the world (McCann and Kim 2003). Neocolonialism is literally 'new colonialism', which includes 'any and all forms of control of prior colonies or populations such as Indigenous people who continue to live under conditions of internal colonialism' (Reimer Kirkham and Browne 2006, 334). Postcolonial perspectives seek to expose these colonizing processes and their subsequent impact on contemporary structures and systems that create and sustain colonial oppression. Edward Said (1979), a significant figure in postcolonial scholarship, emphasized the role of Eurocentrism in forming the foundation for justifying colonialism. Said questioned the supremacy of European knowledge and lifeways and offered a critical examination of persistent and aggressive Eurocentric assimilation plans. Franz Fanon's (1961) book The Wretched of the Earth provided a counter-hegemonic, emancipatory discourse that continues to be relevant in the examination of colonialism and neocolonialism in nursing today. Although his work has since been critiqued by feminist and postcolonial theorists due in part to sexism and racism in his conceptualization of women (colonizing and colonized) in the colonies (Haddour 2010), Fanon called for a redistribution of wealth and economy, and fair resources and rights distribution that would end colonial rule.

The writings of Leela Gandhi (1986), the emergence of critical theoretical perspectives of feminism through the writings of authors such as Patricia Hill Collins (2000) and bell hooks (2003), the critical social projects of Freire (1970), Habermas' critical social theory (1962), critical race theory (Bannerji 2000) and Homi Bhabha's (1994) theorizing about the location of culture vis a vis colonizers and the colonized, have all contributed to a robust discourse supporting action to identify, resist and transform the various forms and consequences of colonialism. There is no single way to describe the nature and scope of postcolonial theory, and the ideas, language and understandings are constantly evolving. Despite this heterogeneity, there are unifying themes that cut across the various discourses informing postcolonial theory. As this article demonstrates, these themes are foundational in action to work toward decolonizing nursing.

\section{A focus on colonized subjectivities and imperialism}

Postcolonial theory involves thinking about the nature of colonized subjectivities and the many forms of cultural and political resistance (Reimer Kirkham and Anderson 2002). Although the term 'subjectivity' has many meanings, including being a subject of a nation-state, here, we use subjectivity as a concept that refers to the cultural, social, political and psychological processes that shape and determine who we think we are and how we situate ourselves in the world. Contemporary concepts of subjectivity emphasize the links among power, language and identity and the fundamental interdependence of human beings with their environment (Harting 2005). Colonization is the deliberative process of shaping Indigenous subjectivities to reflect and internalize Eurocentric hegemony - the socially constructed superiority of white Europeans and the inferior, savage and child or animal-like nature of Indigenous peoples (Hodgson 2009). Anne Bishop (2002) described how internalized racism became important in the creation of Indian residential schools in Canada - a church- and state-sanctioned example of 'child abuse being used to force a people to internalize what their conquerors thought to be their rightful place in a racist, sexist, class-stratified society' (72).

Residential schools were designed and funded by the Canadian government and sanctioned and put into practice by organized religions (e.g., Anglican, Baptist, Catholic, Pres- 
byterian and United Churches). Government-trained Indian Agents abducted children from their families and forcibly removed them for deportation to the schools, often under threat of harsh, punitive measures. These schools were implemented in the context of federal policies intent upon the complete assimilation of Indigenous peoples into the Eurocentric Canadian 'norm' of the colonizers. One of the main goals of the schools was to eliminate parental involvement in the intellectual, cultural and spiritual development of Aboriginal children (Truth and Reconciliation Commission of Canada 2013). Pervasive and long-term harms included the systematic suppression of ancestral languages, culture and Indigenous spirituality; the provision of substandard living conditions and intentional Tuberculosis infection; and a second-rate education that involved widespread physical, sexual, emotional and spiritual abuse (Aboriginal Healing Foundation 2002). Over 50000 Indigenous children died in these schools through neglect or murder - a genocide that has only recently been publically acknowledged (Annett 2010). Indian residential schools remain a disturbing example of how religion, including Western forms of Christian religiosity, played a pivotal role in imperialist domination of Indigenous peoples. Leaders and followers of Britain's Christian churches were strong advocates of a united white empire overseas. Colonized British territories provided substantive opportunity for the churches, which used the colonies as another mission field where churches played a strong role in implementing the principles and procedures of imperialism (Carey 2011).

Indigenous scholar Linda Tuhiwai Smith (2012) states that postcolonial scholarship analyzes how imperialism frames the international Indigenous experience and that Indigenous peoples' writing about their experiences under colonialism has become a significant project in the Indigenous world. Indigenous peoples 'have had to challenge, understand, and have a shared language for talking about the history, the sociology, the psychology, and the politics of imperialism and colonialism as an epic story telling of huge devastation, painful struggle, and persistent survival' (19). Honouring postcolonial Indigenous knowledge, and the reclaiming of Indigenous voice and vision, is an integral aspect of the postcolonial project of self determination (Battiste 2000; Paul 2007; Battiste and Youngblood Henderson 2012). However, as Anderson et al. (2003) point out, there is an important distinction between postcolonial theory and postcolonial Indigenous knowledge. Postcolonial theory arises from Western epistemologies and discourses, whereas postcolonial Indigenous knowledge is grounded in the lived experiences of imperialism and colonialism, a dimension that Indigenous peoples know and understand well (Smith
2012). 'While Indigenous knowledge can (and should) be used to inform postcolonial theories, Indigenous epistemologies represent different intellectual endeavours' (Anderson et al. 2003, 23). In the development of postcolonial perspectives, both areas of knowledge can inform each other, while resisting imposition and appropriation (Anderson et al. 2003).

Postcolonial theories have been critiqued for their potential to create delineated boundaries between the colonizer and the colonized, thus implying a binary opposition (Smith 2012). This dichotomy does not acknowledge the complexity of social location and the historical social construction of descriptive categories of race and ethnicity (hooks 1992). Anderson et al. (2009) have also critiqued postcolonial theories for the presumption of an essentialized, shared experience of colonization among colonized peoples, as if the meanings and subjectivities of colonization are the same across peoples and geographies. A robust examination and critique of the intricacies of subjectivity, and its relationship with colonization, continues to form an important foundation for postcolonial theorizing.

\section{Application of a critical social science perspective}

Abuse of social and economic power and violations of basic human rights are major drivers within the process of colonialism. A critical social science perspective attends to questions about the genesis and maintenance of societal power hierarchies, including access to knowledge production and concerns about self, identity, power, economy and social justice (McGibbon and McPherson 2006). Postcolonial theory involves a critical exposure of unjust social structures and processes that cause colonized peoples to have persistently worse positioning in terms of the social determinants of health and indeed overall health outcomes. 'Critical social science is based, in part, on critical social theory (Habermas 1962), which emerged from resistance movements against social injustices such as fascism, colonialism, and racism' (83).

Critical theoretical perspectives are thus centered on critique, resistance, struggle and emancipation (Smith 2012). An overarching aspect of postcolonial theory is a deliberative focus on critical analyses that expose the ways in which ruling relations are an integral foundation for creating and sustaining colonial and neocolonial practices. Although critical social science perspectives are concerned with correcting injustices of any kind, with particular attention to the ways that injustice is historically inscribed, postcolonial feminism in particular 'aims to hear the voices of all marginalized subjects, including those marginalized by historical socio-political domination and by gender' (Anderson et al. 2009, 282). 
Feminist sociologist Dorothy Smith (2005) described relations of ruling as a complex of organized practices, including government, law, business and financial management, professional organizations and educational institutions as well as the discourses and texts that interpenetrate these multiple sites of power. Colonialism is embedded as an integral feature of ruling relations, where dominant discourses continue to silence critical perspectives about systemic racism and sexism, to name a few of the 'isms'. Feminist postcolonial perspectives make explicit the articulation of everyday experience with the unequal distribution of power and the structural or systemic forms of oppression, including marginalization and racialization:

... postcolonialism is inherently concerned with social justice, often on a grand scale that encompasses national power struggles, oppressions, diasporas, and globalization. The goal is not only to illuminate these wider sociopolitical and global issues but to situate individual experiences, and the conditions, policies, and practices that shape those experiences, within these wider contexts.

(Reimer Kirkham and Browne 2006, 334)

Postcolonial feminist theory integrates the concept of intersectionality, another important aspect of the processes of colonialism and its neocolonial iterations. Collins (2000) described how oppressions in society do not operate independently. Rather, they intersect in intricate patterns that compound oppression - models that view each oppression as 'additive', rather than interlocking, fail to stress the centrality of power and privilege. Age, culture, (dis)ability, ethnicity, gender, immigrant status, race, sexual orientation, social class and spirituality are all markers of social location, a powerful determinant of one's access to the social and material necessities of life. Oppressions such as sexism, racism, heterosexism and ageism can and do happen together to produce a complex synergy of material and social disadvantage. Here, synergy implies working together, fusion, coalescence and symbiosis - the parts interacting to form an oppressive whole that cannot be disentangled into any single phenomenon (McGibbon and McPherson 2011). Postcolonial feminist theory explicitly focuses on how intersectionality is a foundational concept for understanding the impact of colonization and for working toward decolonization.

\section{Commitment to the project of working toward decolonization}

Decolonization is an iterative process, rather than an outcome. Postcolonial scholars emphasize that colonial oppression reaches backward and forward as a persistent influence on subjugated peoples (Paul 2006). The concept of 'decolonization' underscores the postcolonial imperative to expose, resist and transform the continuing presence and influence of colonial processes. In his writings on curricular and pedagogical transformation, Donald (2009) argued that work dedicated to the goal of decolonization in Canada must explicitly address the colonial nature of the relationships connecting Aboriginal peoples and Canadians. Donald further explains that although the origins and outcomes were vastly different, the process of colonization happened synergistically among the colonized and the colonizers, and hence, decolonization should integrate this shared history:

If colonialism is indeed a shared condition, then decolonization needs to be a shared endeavour. I am convinced that decolonization in the Canadian context can only occur when Aboriginal peoples and Canadians face each other across historic divides, deconstruct their shared past, and engage critically with the realization that their present and future is similarly tied together. (5)

Wilson and Yellow Bird (2005) describe decolonizing as, 'the intelligent, calculated, and active resistance to the forces of colonialism that perpetuate the subjugation and/or exploitation of our minds, bodies, and lands ... [with] the ultimate purpose of overturning colonial structures and realizing Indigenous liberation' (223). The decolonization process involves affirming and activating paradigms of Indigenous knowledge to reveal the wealth and richness of Indigenous languages, world views, teachings and experiences, all of which have been systematically excluded from history, from contemporary educational institutions and from Eurocentric knowledge systems (Battiste and Youngblood Henderson 2012). Identifying and addressing the persistent reach of neocolonialism, and the imperialism that underpins it, is a central aspect of decolonization. Anderson (2002) posits that a feminist postcolonial stance provides the 'grounds for interrupting ahistorical, generalizing, essentializing, culturalist and racializing discourses' (13). According to Sherwood (2009), decolonization is a method required to shift the current paradigm of Western dominance and colonial amnesia that constructs and maintains poor health status. As such, decolonization holds great promise for all of nursing's intellectual and practice endeavors.

\section{PROCESSES INVOLVED IN THE COLONIZATION OF NURSING}

Although postcolonial ideas and practices may at times be acknowledged in nursing discourses, they have not yet taken hold in nursing's consciousness or political agenda. According to Georges (2003), 'the events and multiple discourses that have brought us to this present moment in nursing 
recede endlessly backward into a Eurocentric cultural context with sexism, racism, and classism at its heart, and we carry this context within us' (45). Nursing has developed within all of the aforementioned contexts of colonization, including the intersections of racism and sexism that inform the colonial project. Embedded beliefs and assumptions provide a foundation for the colonizing of intellectual development in nursing. Similarly, racism and white privilege play a central role in the continued colonization of the profession.

\section{Nursing's colonizing beliefs and assumptions}

Although colonialism is imbued with many foundational beliefs and assumptions, based on their careers in the nursing profession over many years, geographies and identities, the authors have experienced that one of the strongest beliefs driving the persistence of colonial thinking and practices in nursing is that colonialism is a thing of the past, and because it happened a long time ago, we have nothing to do with it and it must be 'over'. A corollary belief is that Indigenous peoples 'need to get over it because we are all more or less equal now'. To set aside colonial histories, nursing educators, researchers, policy-makers and scholars must somehow assume that these historical moments are encapsulated and discrete events, to be understood without their historical context. As such, periods of colonial history are not thought to be influential or relevant in modern nursing and hence are largely absent in nursing discourse. Despite its lack of logic, this view remains a cornerstone of the racist legacy of colonialism in nursing. Nursing's grand theories, critiqued in a subsequent section, demonstrate this erasure of colonial history, as if nurses can somehow create theories that are dissociated from the actualities of people's lives.

Another persistent assumption is that humans can be described as a national and international multicultural mosaic of cultures and peoples. This view supposes a diminishing or an erasure of the facts of imperialism and white privilege that led to wide-spread colonization over centuries. Nursing has adopted the language of multicultural 'diversity', to the near exclusion of this colonial context of power and privilege. A nursing focus on knowledge about cultural practices of diet, dancing and dress has taken us even further away from confronting colonialism in nursing. As Anderson et al. (2003) point out:

Rather than focusing on exotic belief systems of people from different ethnocultural backgrounds, and treating each group as a distinct entity, we are challenged, instead, to examine the unequal relations of power that are the legacy of the colonial past and the neocolonial present, and the ways in which the cultures of dominant groups have redefined local meanings, and dictated social structures, including health care delivery systems. (197)

Nursing discourse is imbued with the belief that we are all equal and thus have equal opportunities to better ourselves and to make the most of our lives. Razack (1998) refers to this belief as 'rights thinking', which is based on the liberal notion that we are all individuals who contract with one another to live in a society where each of us may have the maximum in personal freedom. 'Starting from this premise, there are no marginalized communities of people and no historical relations of power ... we are all just human beings' (17). Nursing knowledge is steeped in an ethos of treating everyone equally, a universalist assumption that dominant culture, experience and ways of knowing are true for all cultures. Consequently, the concept of equity has only recently entered nursing discourse, and it still remains marginalized in the profession. Browne et al. (2005) discuss some of the inherent dangers in nursing's egalitarian discourses:

Despite a commitment to the ideals of egalitarianism and colour-blindness, negative images framed as 'cultural' characteristics can become widely applied as markers of difference, particularly when health professionals have frequent contact with patients who embody manifestations of social problems and impoverishment. Without tools for thinking about poverty as the legacy of forced state dependency, health professionals can associate Aboriginal 'culture' with the cultures of poverty, substance abuse, and dependency and invoke discourses on individual responsibility and choice. (30)

The explicit and implicit perpetuation of these beliefs and assumptions remains sustained in systemic structures such as the education, legal, governmental and healthcare systems. As the nursing profession evolved within and alongside colonialist domination, these same beliefs and assumptions are embedded in nursing history and in present-day nursing knowledge and practices, professional codes of ethics, policy and position papers, and institutional nursing policies and procedures. As such, these beliefs and assumptions form a foundation for the colonization of nursing at pointof-care and in educational and professional policy-making and in nursing scholarship.

\section{The colonization of intellectual development in nursing}

Dominant discursive practices in nursing, from 'evidencebased' - or its latest iteration 'evidence-informed' - clinical practice, to the development of philosophical and theoretical perspectives, have emerged within the frame of coloniz- 
ing and related empiricist ideologies (Holmes, Roy and Perron 2008). Here, we focus on key aspects of how these universalist processes and discourses form much of the backbone of intellectual development in nursing. We emphasize implications related to nursing's metaparadigm and nursing's grand theories. Nursing knowledge is largely based on apolitical, marginalizing and racializing discourses. The nursing metaparadigm (human beings, environment, nursing, health) is an ethically inadequate mode of thinking about health and illness in the context of colonialism, globalization, pan-capitalism and environmental degradation. In the book 'Anti-racist health care practice', McGibbon and Etowa (2009) discussed their experiences in critiquing the problematic nature of models and theories designed to guide practice and new knowledge development in the health fields, including nursing:

An example is the use of the word 'environment', a common term in health care models. People ask us: 'Couldn't we just put racism under the area of 'environment'? In a similar fashion, we have been asked why we can't fit racism into the category of 'support systems' in models for health services for street youth. For us, these questions are akin to finding a needle in a haystack. Yes, theoretically the needle exists and can be found; however, without explicit guidance, this discovery is exceedingly unlikely. More importantly, why do we want to keep it hidden? (34)

Similarly, within the nursing metaparadigm, one would need to somehow unearth complex concepts such as oppression and the social change necessary to address colonialism. Thompson (1992) critiqued the origins of nursing's metaparadigm, where privileged white nurse leaders in the 1970s and 1980s constructed representations of health, nursing, people and environment to secure their own location in a healthcare system dominated by business and medicine (Powers 2002). Critical social science concepts of politics and power were thus absent from the theoretical constructs and the metaparadigm's philosophical underpinnings (Powers). These underpinnings continue to drive nursing's adoption of the discourses of management and market-driven healthcare reform based on the discipline of business, where profit is the ultimate goal.

Nursing's grand theories, also crafted by many of the same white nurse leaders in the 1970 s and 1980 s, continue to create fertile ground for oppression of marginalized and racialized peoples. These theories were initially created to lend credibility to nursing as an academic discipline, and the women who formulated them worked diligently to advance nursing knowledge in the context of the dominance of the medical profession. Although nursing theories have become seriously outdated, they continue to be used for the same purpose of enhancing the 'scientific' basis of nursing (Georges 2003). The theories of Orem and Parse (Tomey and Alligood 2002), for example, have an apolitical focus that promotes colonial, white-privileged practices due to the analytical gaze on the individual, and sometimes the family and community as the unit of analysis, to the exclusion of the historical, societal, political and economic antecedents of health and well-being. In Fawcett's (2005) criteria for analyzing and evaluating nursing's grand and middle range theories, she explained that: 'Analysis involves objective and nonjudgemental descriptions of theories, whereas evaluation involves judgements about the extent to which nursing theories meet certain criteria' (131). Fawcett outlined eight evaluation criteria that may be used to assess nursing theories. However, finding relevance in the everyday world, where people's lives unfold in oppressive circumstances, will have the reader looking for McGibbon and Etowa's (2009) 'needle in a haystack'.

Nursing knowledge continues to be grounded in Western biomedical hegemony and its philosophical premises in positivism. Despite integration of the language of 'holism', nursing science is based on positivist beliefs that the whole can be reduced to the sum of its parts, with nursing school curricula providing a concrete example: adult nursing, pediatric nursing, mental health nursing and so on, as if families, communities or nations exist in these discrete, apolitical forms. A cornerstone of biomedical positivism is empiricism - the claim that a priori facts and truths exist and that knowledge of these facts or truths may be developed from that which is directly observable (Cruickshank 2012). Empiricism is especially problematic because choices about where and how to even look for 'facts and truths' are filtered through the lens of imperialist colonialism. The apolitical, positivist nature of nursing's grand theories continues to hamper progressive and social-action oriented thinking in the nursing profession. In similar ways, 'nursing diagnosis' runs in tandem with nursing theories and further 'sustains conditions of social domination, limits autonomy and responsibility, and oppresses individuals and groups... The discourse of nursing diagnosis appeals to the dominance of empirical analytic science and equates this dominance with professional social status' (Powers 2002, 945). The rhetoric of evidence-based practice, grounded in empiricism (Holmes, Perron and O'Byrne 2006), also becomes open for scrutiny in the context of neocolonization: Evidence according to whom? Evidence according to which worldview? Evidence according to whose voice? 


\section{Racism and white privilege in the nursing profession}

Racism and white privilege have historically been theorized by numerous scholars, including nurses. Areas of discussion include racism as a barrier to health equity and social justice (Anderson et al. 2009); culture, values and racism and their application to nursing (Cortis 2003); teaching about race, racism and health in nursing (Drevdahl 2002); systemic racism toward nurses of color and racialist discourses in nursing (Das Gupta 2009); white privilege in the nursing profession (Puzan 2003); and nurse education through a white lens, including racism in the mentor-student relationship (Scammell and Olumide 2011). However, the concepts of racism and white privilege remain on the margins of mainstream nursing practice and discourse. In her germinal text 'Understanding everyday racism: An interdisciplinary theory', Philomena Essed (1991) described persistent forms of racist discrimination that manifest themselves in systematic, recurrent, familiar practices in the everyday world. Essed noted that racism is a structure, where dominance and discrimination exist and are reproduced through controlling access to, and allocation of, resources. Institutionalized racism, in governance, education, legal and health systems, for example, creates an embedded system of oppression, where racist practices are formalized and legitimated. Racism is also a process that 'does not exist outside every day practice where it is reproduced, reinforced and continually adapts to the ever-changing social, political and economic social conditions' (Essed, 44).

Racism in the nursing profession takes many forms, including discrimination in hiring and promotion practices discrimination experienced in clinical practice, such as being infantilized, marginalized, 'put down', insulted or degraded because of race, ethnicity, or colour (Das Gupta 2009) and the damaging health effects of coping with everyday racism from patients, colleagues and administration (Clarke and Acton 2004), all in the context of societal racism that is persistently experienced 'outside the walls' of paid work. These experiences of ongoing racism form the fabric of everyday life for racialized nurses and are largely invisible for the perpetrators, be they in the individual, face-to-face realm, or at the level of governance and policy-making. As Essed (1991) points out, 'practices with racist implications become in themselves familiar and repetitive, underlying racial and ethnic relations that are actualized and reinforced through these routine or familiar practices in everyday situations' (52). There are numerous studies of racism in nursing across the world, particularly in clinical practice (cf. Omeri and
Atkins 2002 in Australia; Alexis and Vydelingum 2007 in the United Kingdom; Das Gupta 2009 in Canada).

White privilege is the other side of the coin, the hidden side of the racism equation in nursing:

Whiteness is depicted not as a preordained biological property, but as a socially constructed category of race, wherein non-white people are racially designated, while whites escape such designation and occupy positions which allow them to carry on as if what they say is neutral, rather than historically and ideologically situated. While the concept of whiteness may not have much resonance in nursing, it offers another way to talk about racism, one that does not stop with the scrutiny of the racialized Other.

(Puzan 2003, 193)

White privilege is a core pillar of racism in nursing, whether it is individual acts of racism, such as treating Indigenous families unethically in the emergency department, or whether it is deeply entrenched and less identifiable systemic racism, such as lack of university administrative support for increasing Indigenous and black student nurse enrollment. Understanding white privilege is a tricky business because it involves 'nice' nurses, be they practitioners, administrators or policy-makers, being complicit with racism, even if their lack of awareness renders their racism 'invisible'.

Structural or systemic racism in nursing is also largely invisible: nursing elite are dominated by white people (Blackford 2003); Western science, which dominates nursing education, is linked with whiteness (Scammell and Olumide 2011); and historical accounts of nursing's evolution as a profession render invisible the leadership of black and Indigenous nurses. For example, South African nursing education continues to focus on the work done by Florence Nightingale and the missionaries who introduced nursing education and pioneered colonial control of the profession. This view of nursing history is still presented, despite more than a decade of post-Apartheid reconciliation processes (Mulaudzi 2003). Jamaican-born Mary Seacole, who served not only as a nurse, but as a financial benefactress in the Crimean War (1853-56), is invisible in nursing developmental history. Her efforts were overshadowed by publicity given to Florence Nightingale who was white and from an upper class English family (Anionwu 2006).

Scammell and Olumide (2011) use Foucault's (1980) concept of a 'regime of truth' to describe white privilege in nursing. According to Foucault, dominant discourses are created and recreated to privilege the truth of a set of statements - a regime of truth. The authors argue that the power of whiteness and its association with superiority over non-whites 'is so embedded within dominant society, nurs- 
Table 1 White privilege in the nursing profession: what it 'looks like'

When I seek health care, I can be pretty sure that I will encounter a practitioner of my own race

When I am in the hospital and I ask to speak to the 'person in charge', I can be pretty sure that I will be facing a person of my own race

When I read health promotion literature in the waiting rooms of hospitals, clinics, or pharmacies I can be pretty sure that many, if not most, of the faces in the pamphlets will reflect my skin color

If I need special bandages, splints, or prosthesis, I can be pretty sure that the color of the materials used will reflect my skin color

When I attend nursing professional association meetings, I can be pretty sure that most of the persons in positions of importance and decision making in my association are persons of my race

Whether I engage in nursing practice in a hospital or in the community, I can be pretty sure that the board of directors who govern my workplace will be mostly persons of my race

If I decide to lobby my local or national political representatives about a health related issue, it is more than likely that that I will be talking to a person of my race

If I decide to further my education in nursing at the baccalaureate, masters or doctoral level, I can be pretty sure that most of my professors will be persons of my race

When I am not hired for a nursing position, I don't question whether my race was a possible reason for rejection

In my nursing class about the historical influences on health, when I speak up about the discrimination and near starvation of Irish people, at the hands of the British in the potato famine in the mid 1800s, I can be pretty sure that I will not be accused of making an issue of something that is long past and no longer worth dwelling on, or of 'taking things too seriously'

As a student, when I go to the clinical skills lab, I can be pretty sure that the demonstration models will reflect my skin color

Source: Adapted from McGibbon and Etowa (2009).

ing ideology and practice, that it is an unacknowledged but taken-for-granted way of being for white nursing staff' (548).

Table 1 depicts some of the ways that white privilege operates in the nursing profession in Western countries.

\section{STRATEGIES FOR INCREASING THE COUNTER-NARRATIVE}

\begin{abstract}
'This colonization has actively undermined disciplinary education, research and policy development. More importantly, it has distracted scholars from focusing on representational, nursing-centered knowledge development relevant to practice. Nurses must not only recognize that it is within their power to challenge disciplinary colonization, they have an obligation to actively engage in decolonizing actions in order to begin reversing these effects'.
\end{abstract}

(Sochan 2011, 185)

Colonizing thinking and actions permeate the nursing profession, from biomedical hegemony in curriculum and practice to managerial efficiency models in the delivery of nursing care. Development of a consistent counter-narrative is necessary if we are to work toward decolonizing practices. Gustafson (2007) discusses the need to engage in critical self-reflection to come to terms with the impact of the many forms of colonization on nursing. Introspection, in combination with dialogue and action, is needed to re-examine preconceived ideas about nursing and to recognize white privilege and Western and personal worldviews as major influences in nursing. Working toward decolonizing nursing includes a commitment to exposing colonizing ideologies, values and structures embedded in nursing curricula, teaching methodologies and professional development. Academic leaders in particular have an ethical responsibility to influence current and future nurses and their learning and practice environments. This action can be enhanced through role modeling the humility and risk-taking that is necessary to share one's own biases and shortcomings when seeking to decolonize ourselves, our relationships and professional environments. In her book 'Unsettling the settler within', Paulette Regan (2010) describes how the European settler mentality continues to permeate Canadian society. Her work has much to offer the profession of nursing, both in Canada and globally.

Writing form a settler perspective primarily for other settlers, the author [Regan] avoids the trap that so many nonNative scholars fall into - telling Native people how we must live. Instead, she homes in on what settlers must do to fix 'the settler problem'. By this, she means that non-Natives must struggle to confront their own colonial mentality, moral indifference, and historical ignorance as part of a massive truth telling about Canada's past and present relationship with the original inhabitants of this land.

(Alfred, $\mathrm{x}$ ) 
The author argues that the settler version of national history - and we would add 'the settler version of the profession of nursing' - denies a critical Indigenous counter-narrative to dominant settler discourses. Given these many deeply engrained barriers to action, and the inherent complexities regarding development of anti-colonial perspectives in nursing, decolonization seems an impossible ideal. However, there are already well-developed pathways to guide action.

\section{Committing to action based on critical social justice and human rights}

A feminist postcolonial lens or stance is inextricably linked to the ideal of social justice (Anderson et al. 2009). Critical social justice, in particular, can guide nurses to identify systemic power structures and their origins in colonialist imperialism (Anderson et al.). A foundation of working toward social justice is learning about, and engaging in, anti-oppressive practice where institutionalized racism and colonizing practices are explicitly linked to societal power structures and processes. Georges (2003) points to an emerging shift in nursing discourses, one that encompasses epistemic diversity, which focuses on:

... a critique of dominant practices, both locally and globally; an emphasis on social justice as a central teleology of nursing scholarship; the importance of the inclusion of multiple voices in the dialogue regarding nursing scholarship; and a fundamental awareness of the salience of context, with the integration of our inner selves into our professional endeavors. (51)

Although social justice does not lend itself to a single definition, the concept represents an underlying unity of ideas based on common goals and aspirations within a societal and global context. Social justice refers to the overall fairness of a society in its divisions of rewards and burdens, and a scrutiny of how human rights are ensured or violated. In the field of health inequities, and related inequities in the social determinants of health, social justice is most often grounded in a perspective that confronts the social, economic and political origins of inequities - the root causes of injustice (World Health Organization 2008). According to Kelly et al. (2008), social justice is awareness, knowledge and behavior based upon a commitment to the values of equity, access and justice; a dedication to civic involvement and environmental sustainability; and a respect for diversity, pluralism and freedom of expression. Social justice is an idea that reminds us 'that public health is indeed a public matter, that societal patterns of disease and death, or health and wellbeing, of bodily integrity and disintegration, intimately reflect the workings of society and politics - for good and for ill' (Krieger and Birn 1998, 1603).

Consistent with critical social science perspectives, 'critical', in the context of social justice, refers to sustained attention to the causes-of-the-causes of inequities and a human rights-based approach to practice and policy-making. In the absence of these inter-dependent foundations of critical social justice, a commitment to action may be largely hollow. At best, resulting action will skim the surface of the roots of injustice - 'social justice light'. At worst, the use of social justice language in policies, curriculum documents and research proposals, for example, without attention to root causes and social power and privilege, results in a capacity to claim action without the ethical commitment to follow through. In the context of decolonizing nursing, enacting critical social justice is about engaging in social change. Although daunting, this iterative process has many entry points for nurses in all realms of their intellectual and practical work.

The operative word is 'action' - social change cannot happen without concrete commitment to actions in the everyday world. Such change happens along a continuum, from supporting and actively participating in oppressive practices and processes, to confronting oppression through initiation of anti-oppressive strategies and prevention (Wijeyesinghe, Griffin and Love 1997). One of the most important starting points in working for social change to decolonize nursing is to embrace the fact that oppressions often flourish without nurses being able or willing to name their oppressive actions. Nurses support oppression when they actively participate in oppression; deny or ignore oppression; or recognize oppression, but take no action. Noticing or witnessing oppression, and taking the moral stance that it is none of our business, or that it is someone else's responsibility to speak up, is the same as not doing anything in the face of need - silence is assent. The International Council of Nurses (2011) position statement on Nurses and Human Rights states:

\footnotetext{
Nurses are accountable for their own actions and inactions in safeguarding human rights, while national nurses associations have a responsibility to participate in the development of health and social policy and legislation related to patient rights ... Nurses individually and collectively through their national nurses associations have a duty to report and speak up when there are violations of human rights ... (1-2) Although the justiciability of these rights remains a considerable challenge (Henrey et al. 2009), they nonetheless lay out a collective vision for enactment of global social justice.
}

One of the main barriers to decolonizing nursing is that social justice and human rights are not at the forefront in 
any measureable or substantive way, despite some of nursing's justice-based historical origins. Examination of many nursing codes of ethics, professional practice guidelines, mission statements, curricular documents and local and national guiding documents reveals that the language of human rights and justice is sporadic (McGibbon and Etowa 2009), thus undermining efforts to consistently tackle oppression in the form of colonialism. Decolonization is bound up within global pan-capitalism, imperialism and the violation of civil and human rights. When a critical mass of nurses understands this global context, especially within the profession's persistent embrace of positivism, it can be a pivotal moment for decolonizing action.

\section{Insisting on sustained attention to the structural determinants of health}

The continued colonization of nursing knowledge and practices indicates that the profession has reluctantly and inconsistently embraced the structural determinants of health. This reluctance continues to hamper the development of a counter-narrative to colonizing practices. In keeping with a postcolonial feminist lens for change, knowledge and action for decolonizing nursing knowledge and practices could fruitfully be informed by a consistent and explicit focus on these structural determinants of health. Here, 'structural' refers to the economic, social and political structures of society and the moral and cultural systems that underpin them (McGibbon, Waldren and Jackson 2013). Emphasis is directed to the role of the economic organization of society in the production and distribution of disease and burden of illness, and the ways that disease and illness are framed and treated (McGibbon and Shebib 2012). Structural perspectives on health and health-care focus on context - public policy questions about how some groups of people persistently have worse health than others, and how some countries have public policies that lead to more effective and democratic healthcare systems and consequently better citizen health. Although the income inequality model, often cited as an antecedent of health inequality, acknowledges the relationship between income and health, it stops short of connecting the poor health of poor people to race and class inequality in capitalist societies (Muntaner and Lynch 2002).

Economic and racial inequality are not abstract concepts, [they] hospitalize and kill even more people than cigarettes. The wages and benefits we're paid, the neighborhoods we live in, the schools we attend, our access to resources and even our tax policies are health issues every bit as critical as diet, smoking, and exercise.

(Adelman 2008, cover)
Nursing's reductionist and empiricist foundations obscure these structural causes of inequities in health. The physical and mental health status of Indigenous peoples can best be traced to the tyranny of white colonial power, not deficits in 'lifestyle'. The healthy-lifestyle-choice discourse shifts the locus of responsibility and intervention to the individual level, rather than toward systemic social change to address health inequities. Nurses urgently require knowledge about processes of public policy planning, implementation and evaluation. Although public policy has been integrated in graduate programs (Ridenour and Trautman 2009) in countries such as Canada and the United States (US), there is limited evidence that it is on the education agenda for undergraduate nurses or for practicing nurses. In their call for nurses to become active in aiming for universality in health-care in the Unites States, Ridenour and Trautman stated: 'nurses can and should attend to the politics of change by using policy as a leveraging tool for widespread social change (360)'.

\section{CONCLUSION}

Decolonization is one of the most important processes for the continued relevance of the nursing profession. Nursing's positivist, individualistic and Eurocentric foundations seriously hamper the growth of the profession and nurses' professional capacity to collectively confront the root causes of health inequities. We argue that decolonization, viewed as a discrete and peripheral concern in mainstream nursing, is actually a path to urgently needed growth and transformation for the entire profession. This article underscores the complex synergy of ideas and action that can continue to increase the counter-narrative to nursing's continued colonization.

\section{ACKNOWLEDGEMENTS}

We would like to acknowledge the Canadian Institutes for Health Research (\#68909) for their generous support of the work that led to this manuscript. As a posthumous tribute, we dedicate this article to Dr. Dawn Smith, who dedicated her life's nursing practice in the pursuit of social justice for all.

\section{REFERENCES}

Aboriginal Healing Foundation (AHF). 2002. The healing has begun. Ottawa, ON: AHF.

Adelman L. 2008. Unnatural causes: Is inequality making us sick? San Francisco, CA: California Newsreel. 
Alexis $\mathrm{O}$ and V Vydelingum. 2007. Migrating registered nurses in the United Kingdom: Black and minority ethnic overseas nurses' perspectives. International Journal of Health Care Quality Assurance 20: 441-52.

Anderson JM. 2002. Toward a post-colonial feminist methodology in nursing research exploring the convergence of post-colonial and feminist scholarship. Nurse Researcher 9: 720.

Anderson JM, J Perry, C Blue, A Browne, A Henderson, $\mathrm{K}$ Khan et al. 2003. Rewriting cultural safety within the postcolonial and postnational feminist project toward new epistemologies of healing. Advances in Nursing Science 26: 196-214.

Anderson JM, P Rodney, S Reimer Kirkham, RP Browne, A Khan and JM Lynam. 2009. Inequities in health and healthcare viewed through the ethical lens of critical social justice: Contextual knowledge for the global priorities ahead. Advances in Nursing Science 32: 282-94.

Anionwu E. 2006. About Mary Seacole. Thames Valley University, London: Mary Seacole Center for Nursing Practice.

Annett K. 2010. Hidden no longer: Genocide in Canada, past and present. The International Tribunal into Crimes of Church and State and the Friends and Relatives of the Disappeared: Published on Occupied Territory of the Squamish Indigenous Nation.

Bannerji H. 2000. The dark side of the nation: Essays on multiculturalism, nationalism, and gender. Toronto, ON: Canadian Scholars Press.

Battiste M. 2000. Reclaiming Indigenous voice and vision. Vancouver, BC: University of British Columbia Press.

Battiste M and S Youngblood Henderson. 2012. Oppression and the health of Indigenous peoples. In Oppression: A social determinant of health, ed. E McGibbon, 89-96. Halifax: Fernwood Publishing.

Bhabha H. 1994. The location of culture. London: Routledge.

Bishop A. 2002. Becoming an ally: Breaking the cycle of oppression. Halifax: Fernwood Publishing.

Blackford J. 2003. Cultural frameworks of nursing practice: Exposing an exclusionary healthcare Culture. Nursing Inquiry 10: 236-44.

Browne A, V Smye and C Varcoe. 2005. The relevance of postcolonial theoretical perspective to research in Aboriginal health. Canadian Journal of Nursing Research 37: 1637.

Carey HM. 2011. God's empire: Religion and colonialism in the British world, c. 1801-1908. Cambridge: Cambridge University Press.

Clarke J and J Acton. 2004. Racism is layers and layers of things that break your spirit and damage your community. Racism,
Violence and Health Project. Halifax: Dalhousie University.

Collins PH. 2000. Black feminist thought: Knowledge, consciousness, and the politics of empowerment. New York, NY: Routledge.

Collins PH. 2005. Black sexual politics: African Americans, gender, and the new racism. New York, NY: Routledge.

Cortis JD. 2003. Culture, values and racism: Application to nursing. International Nursing Review 50: 55-64.

Cruickshank J. 2012. Positioning positivism, critical realism and social constructionism in the health sciences: A philosophical orientation. Nursing Inquiry 19: 78-82.

Das Gupta T. 2009. Real nurses and others: Racism in nursing. Halifax: Fernwood Publishing.

Donald D. 2009. Forts, curriculum, and Indigenous métissage: Imagining decolonization of Aboriginal-Canadian relations in educational contexts. First Nations Perspectives 2: 1-24.

Drevdahl D. 2002. Teaching about race, racism, and health. Journal of Nursing Education 40: 285-9.

Essed P. 1991. Understanding everyday racism: An interdisciplinary theory. Newbury Park, CA: Sage Publications.

Fanon F. 1961. The wretched of the earth. New York, NY: Grove Press.

Fawcett J. 2005. Criteria for evaluating a theory. Nursing Science Quarterly 18: 131-5.

Foucault M. 1980. Michael Foucault: Power/knowledge: Selected interviews and other writings, 1972-1977. Brighton: Harvester Press.

Freire P. 1970. Pedagogy of the oppressed. New York, NY: Continuum.

Gandhi L. 1986. A complicated occidentalism: Colonial desire and disappointment. New York, NY: Columbia University Press.

Georges JM. 2003. Emerging discourses: Toward epistemic diversity in nursing. Advances in Nursing Science 26: 44-52.

Gustafson DL. 2007. White on whiteness: Becoming radicalized about race. Nursing Inquiry 14: 153-61.

Habermas J. 1962. The structural transformation of the public sphere. Boston, MA: MIT Press.

Haddour A. 2010. Torture unveiled: Rereading Fanon and Bourdieu in the context of May 1958. Theory, Culture \& Society 27: 66-90.

Harting H. 2005. Subjectivity. Globalization and Autonomy Online Compendium. http://www.globalautonomy.ca/ global1/glossary_entry.jsp?id=CO.0036 (accessed 20 January 2013).

Henrey F, C Tater, W Mattis and T Rees. 2009. The color of democracy: Racism in Canadian society. Toronto, ON: Harcourt Canada. 
Hodgson L. 2009. Nature, nurture, nation: Race and childhood in transatlantic American discourses of slavery. PhD diss., University of Southern California, Los Angeles, CA.

Holmes D, A Perron and P O'Byrne. 2006. Evidence, virulence, and the disappearance of nursing knowledge. Worldviews on Evidence-Based Nursing 3: 95-102.

Holmes D, B Roy and A Perron. 2008. The use of postcolonialism in the nursing domain: Colonial patronage, conversion, and resistance. Advances in Nursing Science 31: 42-51.

hooks b. 1992. Black looks: Race and representation. Boston, MA: South End Press.

hooks b. 2003. Teaching community: A pedagogy of hope. London: Routledge.

International Council of Nurses (ICN). 2011. ICN position statement on human rights. Geneva: International Council of Nurses (ICN).

Kelly MA, A Connor, KE Kun and LE Salmon. 2008. Social responsibility: Conceptualization and embodiment in a school of nursing. International Journal of Nursing Education Scholarship 5: 1-16.

Krieger N and AE Birn. 1998. A vision of social justice as the foundation of public health. American Journal of Public Health 88: 1308-13.

McCann CR and S-K Kim. 2003. Feminist theory reader: Local and global perspectives. New York, NY: Routledge.

McGibbon E and J Etowa. 2009. Anti-racist health care practice. Toronto, ON: Canadian Scholar's Press.

McGibbon E and C McPherson. 2006. Interpretive pedagogy in action: Design and delivery of a violence and health workshop for baccalaureate nursing students. Journal of Nursing Education 45: 81-5.

McGibbon E and C McPherson. 2011. Applying intersectionality theory and complexity theory to address the social determinants of women's health. Women's Health and Urban Life 10: 59-86.

McGibbon E and M Shebib. 2012. Human rights and health: Challenges and supports for accountability. In Oppression: A social determinant of health, ed. E McGibbon, 186-203. Halifax: Fernwood Publishing.

McGibbon E, I Waldren and J Jackson. 2013. The social determinants of cardiovascular disease: Time for a focus on racism (Guest editorial). Diversity and Equality in Health and Care (in press).

Mulaudzi FM. 2003. A tribute to Indigenous healers. Nursing Update 27: 22-4.

Muntaner C and JW Lynch. 2002. Social capital, class and race political conflict and population health: Implications of the 'Bowling Alone' hypothesis for research, philosophy and health policy. International Journal of Epidemiology 31: 261-67.

Omeri A and K Atkins. 2002. Lived experiences of immigrant nurses in New South Wales, Australia: Searching for meaning. International Journal of Nursing Studies 39: 495-505.

Paul D. 2006. We were not the savages: Collision between European and Native American civilizations. Halifax: Fernwood Publishing.

Paul D. 2007. We were not the savages: Collision between Native and North American civilizations. Halifax: Fernwood Publishing.

Powers P. 2002. A discourse analysis of nursing diagnosis. Qualitative Health Research 12: 941-61.

Puzan E. 2003. The unbearable whiteness of being in nursing. Nursing Inquiry 10: 193-200.

Razack S. 1998. Looking white people in the eye: Gender, race, and culture in courtrooms and classrooms. Toronto, ON: University of Toronto Press.

Regan P. 2010. Unsettling the settler within: Indian residential schools, truth telling and reconciliation in Canada. Vancouver: University of British Columbia Press.

Reimer Kirkham RS and JM Anderson. 2002. Postcolonial nursing scholarship: From epistemology to method. Advances in Nursing Science 25: 1-17.

Reimer Kirkham SH and AJ Browne. 2006. Toward a critical theoretical interpretation of social justice discourses in nursing. Advances in Nursing Science 29: 324-39.

Ridenour N and D Trautman. 2009. A primer for nurses on advancing health reform policy. Journal of Professional Nursing 25: 358-62.

Said EW. 1979. Orientalism. New York, NY: Vintage Books.

Scammell JME and G Olumide. 2011. Racism and the mentor-student relationship: Nurse education through a white lens. Nurse Education Today 32: 545-50.

Sherwood J. 2009. Who is not coping with colonization? Laying out the map for decolonization. Australian Psychiatry 17: $24-7$.

Smith D. 2005. Institutional ethnography: A sociology for the people. Oxford: AltaMira Press.

Smith LT. 2012. Decolonizing methodologies: Research and Indigenous peoples. Hants: Zed Books.

Sochan A. 2011. Stance and strategy: Post-structural perspective and post-colonial engagement to develop nursing knowledge. Nursing Philosophy 12: 177-90.

Thompson JL. 1992. Identity politics, essentialism, and constructions of "home" in nursing. In Critique, resistance, and action: Working papers in the politics of nursing, eds JL Thompson, DG Allen and L Rodrigues-Fisher, 21-34. New York, NY: National League for Nursing. 
Tomey AM and MR Alligood. 2002. Nursing theorists and their work, 3rd edn. Philadelphia, PA: Mosby.

Truth and Reconciliation Commission of Canada. 2013. Residential schools. http://www.trc.ca/websites/trcinstitution/index.php?p=4 (accessed 10 February, 2013).

Varcoe C. 2004. Widening the scope of ethical theory, practice and policy: Violence against women as an illustration. In Toward a moral horizon: Nursing ethics for leadership and practice, eds J Storch, P Rodney and R Starzomski, 414-32. Toronto, ON: Pearson.
Wijeyesinghe CL, P Griffin and B Love. 1997. Racism curriculum design. In Teaching for diversity and social justice: A sourcebook, eds M Adams, L Bell and P Griffin, 82-107. New York, NY: Routledge.

Wilson WA and M Yellow Bird. 2005. For Indigenous eyes only: A decolonization handbook. Santa Fe: School of American Research.

World Health Organization (WHO). 2008. Closing the gap in a generation: Health equity through action on the social determinants of health. Geneva: WHO. 